\title{
Modelo de Apoio à Decisão de Roteamento na Distribuição Física de Produtos Perecíveis
}

\author{
Fábio Roberto Salata Jr.
}

Engenheiro de Produção,

Pão Americano S/A

\section{Hugo T.Y.Yoshizaki}

Professor Assistente,

Depto. de Engenharia de Produção, Escola Politécnica, USP.

Caixa postal 61548, São Paulo -SP, 05508.

Palavras-chave: logística; Distribuição Física; Pesquisa Operacional; Roteirização.

Key words: logistics; Physical Distribution; Operations Research; Routing.

\section{RESUMO}

Este trabalho descreve o desenvolvimento de um modelo de apoio à decisão de roteamento numa indústria de produtos alimentícios. Esta sistemática utilizou o algoritmo SWEEP, obtendo economias significativas em relação à forma anterior de programação de roteiros. O modelo, por outro lado, auxiliou a desvincular as operações do canal de vendas e do canal de distribuição fĩsica. Montou-sc também uma série de indicadores de produtividade para a entrega de produtos, permitindo melhor controle gerencial desta atividade.

\section{ABSTRACT}

This work describes the effort to construct a decision support model for fleet routing in the distribution of a food industry. The SWEEP algorithm was employed, obtaining better results than the previous approch. On the other hand, the model helped to segregate distribution channel operations of sales and physical sistribution. A set of productivity indicators was also developed to allow better managerial control of that activity. 


\section{Introdução}

Este trabalho foi desenvolvido numa indústria de produtos alimentícios, com foco na distribuição física de perecíveis na região metropolitana de São Paulo (Salata Jr., 1990). Seu objetivo foi desenvolver um método adequado de administração dos roteiros para distribuição urbana na empresa, obedecendo parâmetros de nível de serviço, produtividade e prática administrativa vigente.

Elaborou-se, desta maneira, uma sistemática tanto para a formação de rotas de entregas para os veículos da firma (roteirização), com a capacidade de ser flexível às variações que ocorrem diariamente nas vendas realizadas, como para o controle dessas operações, através de uma série de indicadores de produtividade.

O resultado obtido no teste-piloto foi, para a amostra analisada, uma redução significativa do número de viagens, juntamente com uma melhoria em um equilibrio dos índices de produtividade, ou seja, no uso de recursos na distribuição. Atualmente, procede-se à implantação do modelo nas demais regiões de entrega na cidade.

Este projeto foi desenvolvido como o trabalho de formatura do primeiro autor, sob a orientação do segundo, no ano de 1990.

\section{Metodologia Empregada}

Foi utilizado o enfoque sistêmico (Churchman, 1986) no desenvolvimento deste trabalho.

Inicialmente, procedeu-se à definição do problema, com a identificação do sistema de entregas, dos seus objetivos e do seu ambiente. Foi também necessária a formalização pela empresa do nível de serviço de atendimento a ser oferecido aos seus clientes. Realizou-se então a coleta de dados e informações sobre: produtos, instalações, sistema de controle, estatísticas de vendas, sistemas administrativos, mercados e canais de distribuição, custos logísticos etc. Este levantamento permitiu definir o sistema a ser estudado, onde a roteirização de entregas era tradicionalmente realizada por métodos empíricos.

Em seguida, procedeu-se à definição de medidas de mérito para as sistemáticas atual e futura, com a formação de indicadores de produtividade física. Com os dados coletados foram então calculados os diversos desempenhos para as rotas originais.

A partir dessas informações, foi realizada a análise da situação vigente e a proposição de alternativas para melhoria. Foram pesquisados diversos algoritmos de roteirização, tendo sido escolhido o algoritmo Sweep (Ballou, 1987). Foram então determinadas uma região-piloto da área metropolitana e um período de amostragem, com a finalidade de validar os procedimentos propostos, e permitir tomar-se a decisão de implantação do novo método.

\section{Descrição do Problema}

O sistema em questão é responsável pela entrega diária de produtos aos clientes da indústria (grandes e pequenos varejistas, cerca de 2000 entregas por dia, 65 zonas de distribuição) na região metropolitana de São Paulo. Ele conta com uma frota de veículos próprios da empresa (basicamente, 80 caminhões de 3,5 t) e uma equipe de motoristas/ ajudantes. 
O nível de Serviço adotado pela empresa é atender todos os pedidos dos clientes no dia seguinte à emissão, mesmo que isto acarrete na entrega de pedidos incompletos.

Os veículos saem no início do dia de um único armazém central (contíguo à fábrica), sendo que geralmente atendem mais de um cliente por viagem (entrega parcelada). Para tanto, o setor de vendas passa diariamente, até as $15 \mathrm{~h}$, os pedidos que serão entregues no dia seguinte para processamento e triagem. Os roteiros são montados, os caminhões são carregados conforme os roteiros na madrugada $e$ as entregas são iniciadas às 6 horas da manhã. Para a análise desta sistemática foi elaborado o Diagrama de Fluxo de Dados (DFD) e determinados os tempos dispendidos em cada processo. O estudo dos tempos e das atividades paralelas foi importante para definir o tempo disponível para o processamento do modelo de apoio à roteirização e a escolha do algoritmo.

Originalmente a região metropolitana era dividida em zonas de entrega fixas, que eram as mesmas tanto para a operação de vendas como para entregas. Além disso, cada vendedor e cada motorista trabalhava em apenas uma única zona de distribuição. Isto prejudicava o desempenho da distribuição física, uma vez que as naturezas das operações de vendas e entregas são bastante diferenciadas, com os caminhões operando em média com uma ocupação de apenas $50 \%$ do baú. Uma das características da nova sistemática é justamente a desvinculação entre zonas de venda e zonas de entregas, permitindo à distribuição fisica uma melhor adaptação às suas atividades e natureza de operações. Uma discussão sobre esta interferência em canais de distribuição pode ser vista em Bowersox et alii (1985) e em Kotler (1980).
Existem 7 famílias de produtos, sendo que uma delas (pães de forma) responde por $50 \%$ do volume físico das entregas (devido à sua baixa densidade, os produtos da empresa são críticos em volume e não em peso na lotação de um caminhão). Uma característica importante é a perecibilidade dos produtos ( 7 a 15 dias em regra), tendo a principal família a maior perecibilidade. Isto tem implicações no nível de serviço e na programação de entregas, em termos da freqüência de visitas a um mesmo cliente.

Existe uma sazonalidade de ciclo semanal nas vendas, com o pico ocorrendo na sextafeira e sábado e o vale na segunda-feira, o pico sendo $40 \%$ superior ao vale.

\section{Desenvolvimento do Trabalho}

Para a definição de um método (algoritmo) de roteirização, foram necessárias duas informações básicas, além da demanda por produtos e oferta de recursos:

$1^{\circ}$ ) índices de produtividade (desempenho) de cada rota atual;

$2^{\circ}$ ) a posição geográfica dos clientes e a rede de vias (base de dados geográfica).

\section{Índices de Produtividade Física}

Um dos principais pontos do trabalho foi a geração de um conjunto de indicadores de produtividade para a distribuição das mercadorias, uma vez que o setor tinha sido recentemente estruturado e havia falta de ferramentas gerenciais. Essa necessidade de informações foi parcialmente atendida pelos indicadores físicos descritos mais abaixo. 
O uso destes indicadores parciais permitiu o conhecimento de alguns pontos críticos, ao distinguir o desempenho para cada zona e região de entregas da Grande São Paulo. Foram coletados dados pelo período de um mês de operações, considerado pela administração como suficiente mediante a ciclicidade semanal das vendas.

Os indices elaborados são os seguintes:

a) Ocupação: volume de carga entregue/volume disponível nos baús (OCU);

b) Quantidade média de cestas (unidade de movimentação) entregue para cada cliente (MCE);

c) Tempo médio para deslocamento de um cliente a outro (MTP);

d) Razão entre o tempo dispendido para atender desde o primeiro ao último cliente da zona e o tempo total que o veículo está fora da empresa (TZN);

e) Razão entre o tempo que o veículo está fora da empresa e o tempo normal de serviço de $8 \mathrm{~h} / \mathrm{dia}$ (TDI).

Ao se analisar todas as zonas de entrega, verificou-se, além da baixaocupação média, uma grande heterogeneidade nos indices para diferentes zonas. A análise da produtividade permitiu escolher 4 zonas contíguas e de desempenho inadequado para montar o teste-piloto para validação do modelo proposto. Os índices agregados para a região formada por estas 4 zonas estão na tabela 1 abaixo.

\section{Base de Dados Geográficos}

Para a realização dos testes e validação do modelo, foi necessário desenvolver a base de dados geográficos da região escolhida. As informações da rede de clientes e de vias de acesso naturalmente dependem do tipo de modelo escolhido para o roteamento, e vice-versa, num processo interativo. Neste caso, foram marcados num mapa todos os clientes atendidos para cada dia da semana numa semana considerada típica. A escolha de um periodo de uma semana para a validação se deve à sazonalidade já comentada.

A visualização gráfica foi fundamental para se familiarizar com a distribuição geográfica dos clientes e suas ligações com as vias de acesso, além da identificação de pontos notá-

TABELA 1. ÍNDICES DA REGIÃO ESCOLHIDA

\begin{tabular}{lccccccc}
\hline Ind./Dia & SEG & TER & QUA & QUI & SEX & SAB & MÉDIA \\
\hline OCU & 0,35 & 0,42 & 0,50 & 0,42 & 0,59 & 0,35 & 0,44 \\
MCE & 3,06 & 4,34 & 2,82 & 3,5 & 5,82 & 3,59 & 3,86 \\
MTP (h) & 0,18 & 0,23 & 0,20 & 0,18 & 0,22 & 0,16 & 0,19 \\
TZN & 0,71 & 0,74 & 0,82 & 0,73 & 0,67 & 0,67 & 0,72 \\
TDI & 0,86 & 0,92 & 1,31 & 0,92 & 1,03 & 0,72 & 0,96 \\
\hline
\end{tabular}


veis, como rios, pontes, grandes avenidas etc. Também foi importante diferenciar grandes clientes (como hipermercados, que têm prioridade de entrega e restrições de horário) dos demais.

\section{Escolha do Modelo}

Para a definição de um modelo apropriado para montar os roteiros, foram pesquisados diversos algoritmos existentes na literatura (Fisher e Jaikumar (1981), Clarke e Wright (1964), Bodin et alii (1983)). Foram analisados tanto algoritmos otimizantes como heurísticos.

Uma questão importante era desvincular as zonas de entrega das zonas de venda, e deixar a formação de roteiros livre e não mais fixa, de forma a homogeneizar o desempenho das diversas rotas.

Além disso, existe uma série de restrições, muitas das quais associadas aos clientes. $\mathrm{O}$ uso de heurísticas foi considerado como mais apropriado, devido à flexibilidade e rapidez de rotas. Alguns dos parâmetros importantes para a escolha do modelo são: horários de entrega, capacidade dos baús dos caminhões, prioridade de clientes etc.

Foi escolhido o algoritmo SWEEP (vide Bodin er alii, 1983, p.170) para implementação, com devidas adaptações. Várias razões levaram a esta escolha, a saber:

a) disponibilidade e confiabilidade das informações coletadas - os pontos de entrega não foram tabulados com coordenadas individuais no mapa, mas sim agregados em quadrantes;

b) simplicidade do algoritmo - permitiu gerar rapidamente resultados para comparação, e, portanto, agilizou sua avaliação pelos administradores da área; por outro lado, seu funcionamento é de fácil compreensão pelo usuário, o que auxiliou bastante sua aceitação;

c) organização da área - o setor tinha sido estruturado recentemente, e muitos procedimentos novos estavam sendo implantados ou planejados, gerando grande incerteza a médio e longo prazo; desta maneira, era prudente adotar um modelo cujo desenvolvimento não consumisse muito tempo e rapidamente gerasse resultados, auxiliando a estruturar o setor e atuando como um protótipo de sistema de roteirização (Davis, 1982). Posteriormente poderia ser implantado um modelo mais sofisticado, que desse melhores resultados e necessitasse de mais informações.

$O$ algoritmo SWEEP tem duas fases: na primeira, ele agrega os pontos de entrega em um ou mais conjuntos; em seguida, determina a sequiência dos roteiros por regras mais ou menos complicadas.

A fase de agregação consiste em:

1) determinar no mapa a região de abrangência dos clientes a serem atendidos;

2) determinar um ponto $A$ qualquer do plano como referência;

3) varrer, centralizado em A, sucessivos setores geométricos adjacentes até completar toda a região, obedecendo todas as restrições impostas ao sistema. A varredura pode ser feita tanto no sentido horário como no anti-horário, recomendando-se traçar o maior número possível de possibilidades através de diferentes pontos e referências (raios) de inicialização. 
A fase de determinação dos roteiros se faz através da seqüenciação dos clientes "varridos" na formação das regiões. É importante considerar, para muitos casos, que o objetivo deste roteiro não é impor com precisão a seqüência de clientes a serem atendidos (itinerário), mas agrupá-los organizadamente quanto às suas proximidades.

O último roteiro montado por este algoritmo tem grande possibilidade de ter menor ocupação do veículo.

A variante do algoritmo SWEEP utilizada levava em conta apenas duas restrições:

1.- número máximo de clientes para cada roteiro (50);

2.- capacidade máxima de cestas para os baús (270).

\section{Resultados}

A aplicação do modelo à região do estudo gerou redução significativa no número de viagens necessário, além da melhoria e do equilíbrio nos índices de produtividade física, ou seja, no uso dos recursos de distribuição. Uma das principais mudanças foi a alocação variável do número de caminhões de entrega para cada dia da semana, de acordo com as necessidades (este número era basicamente fixo). Os resultados obtidos comparados com os valores reais da semana amostrada estão na tabela 2, abaixo.

\section{Conclusões}

A implantação dos indicadores de produtividade física para a distribuição dos antigos procedimentos empíricos para roteirização pelo modelo SWEEP representou um significativo avanço tecnológico na administração logística da empresa.

A fase de implantação da nova sistemática iniciou-se logo após a conclusão deste estudo, tendo havido uma alteração importante na definição das posições geográficas dos clientes, adotando-se agora o sistema CEP dos Correios. Tal mudança não alterou os resultados obtidos. Além disso, o método está sendo codificado no computador da empresa.

TABELA 2. RESULTADOS OBTIDOS

\begin{tabular}{l|c|c|c|c|c}
\hline \multirow{2}{*}{ Dia } & \multicolumn{2}{|c|}{ Método Original } & \multicolumn{2}{c|}{ "SWEEP" } & \multirow{2}{*}{$\begin{array}{c}\text { Ocupação } \\
\text { Baú (\%) }\end{array}$} \\
\cline { 2 - 5 } & $\begin{array}{c}\text { Número } \\
\text { Clientes }\end{array}$ & $\mathbf{N}^{\text {N Viag. }}$ & $\begin{array}{c}\text { Ocupação } \\
\text { Baú (\%) }\end{array}$ & $\mathbf{N}^{\mathbf{0}}$ Viag. & 2 \\
\hline SEG & 63 & 3 & 32,7 & 2 & 79,0 \\
TER & 91 & 4 & 35,4 & 3 & 68,0 \\
QUA & 131 & 4 & 51,0 & 2 & 58,4 \\
QUI & 75 & 3 & 38,9 & 2 & 71,6 \\
SEX & 92 & 4 & 35,8 & 2 & 65,4 \\
SAB & 84 & 4 & 32,7 & 13 & \\
TOTAL & 536 & 22 & & \\
\hline
\end{tabular}




\section{Referências Bibliográficas}

BALLOU, R.H. Basic Business Logistics. Prentice-Hall, New Jersey, 1987.

BODIN, B. GOLDEN, B. A. Assaad e M. Ball. "Routing and Scheduling of Vehicles and Crews: the State of the Art". Comuters and Operations Research, V.10, n.2, 1983.

BOWERSOX. D.J. Logistics Management. 1985.

CHURCHMAN, C. W. The Systems Approach. Dell Publishing, New York, 1968.

CLARKE, G. e WRIGHT, J.W. "Scheduling of Vehicles from a Central Depot to a Number of Delivery Points". Operations Research, V.12, 1964, pp. 568-581.
DA VIS, G.B. "Strategies for Information Requirements Determination". IBM Systems Journal, V.21, n.1, 1982, pp.4-30.

FISHER, M. e JAIKUMAR, R. "A Generalizeed Assignment for Vehicles Routing”. Net-works, V.11, n.2 1981, pp.109-123.

KOTLER, P. Marketing. São Paulo, Atlas, 1980.

SALATA, F.R. Jr. Modelo Logístico de Apoio à distribuição Física em uma Indústria de Produtos Alimentícios. Trabalho de Formatura, Departamento de Engenhariạ de Produção, Escola Politécnica da USP, 1990. 